\title{
Teachers' Knowledge of Special Educational Needs and Disability Students and Their Classroom Management Approaches
}

\author{
Mercedes Nana Konadu Gyasi ${ }^{1}$, Abraham Kwadwo Okrah, ${ }^{2, *} \&$ Joyce Senya Ama Anku \\ ${ }^{1}$ Cass School of Education and Communities, University of East London, Stratford Campus, UK \\ ${ }^{2}$ Department of Teacher Education, University of Ghana, Legon, West Africa \\ *Correspondence: Department of Teacher Education, University of Ghana, Legon, West Africa. Tel: \\ 233-2441-50195. E-mail: aokrah@ug.edu.gh
}

Received: May 29, 2020

Accepted: August 1, $2020 \quad$ Online Published: August 22, 2020

doi:10.5430/wje.v10n4p160

URL: https://doi.org/10.5430/wje.v10n4p160

\begin{abstract}
Parents and many other stakeholders usually complain about equity and inclusivity of students with special educational needs (SEN) in the mainstream schools. The purpose of the study was to find out the level of teachers' knowledge of special educational needs and disability students and their classroom management procedures and strategies. The study adopted qualitative paradigm and a descriptive approach to gather data and were thematically analysed. The findings showed that teachers' knowledge of special educational needs and disability students was very limited. It revealed teachers' lack of in-depth knowledge of inclusivity, enacted and operational policies and their application, and the classroom management procedures and management of students with special educational needs. It is recommended that teachers be examined appropriately and certified before allowing them to teach in schools. Teachers who are already teaching should be updated with the current trend of educational issues including inclusivity, equity and gender sensitivity.
\end{abstract}

Keywords: special needs, disability, education, inclusivity, equity, management

\section{Introduction}

The concept of special educational needs and disability (SEND) has evolved through several decades with different meanings during each evolution (UCLES, 2017). However, special education is viewed as a definitive description of the concept (Rousan, 1998; UCLES, 2017). According to Rousan (1998) special education relates to a study that is concerned with the evaluation, diagnosing and preparation of suitable instructional programs and techniques of teaching and learning that is appropriate for different categories of exceptional children. UCLES (2017) opines that the term refers to students with learning challenges, which makes it difficult for them to learn in comparison to children of the same age group. This means that special education is a means of providing holistic education for students of SEND to enable them to realise their God-given potentials. The SEN Code of Practice (DfES, 2015) defines the term 'special educational need' as: "a learning difficulty which calls for special educational provision to be made" (p: 6).

The concept of special education has both traditional and contemporary notions (Alkahtani, 2016). Traditionally, it began in the eighteenth century in which certain categories of SEND, for example, deafness, were considered. Those children with mental disabilities were included in the nineteenth century. The focus of educationists by then was on the need for provision of support to make life meaningful to those students of SEND.

Today, almost every nation accepts the idea of SEN and the protection of the disabled (Special Attention Project, 2011). In Ghana, for instance, Persons with Disability Act was passed in 2006 by Parliament and this resulted in the write up of 'Overview of Policy and Legislative Framework on Inclusive and Special Education in Ghana (Ankutse, 2019), Regional Special Education and Disability Coordinator, Ghana Education Service (GES); Special Attention Project (2011); Simplified Version of the Persons with Disability Act (2006). The passage of Persons with Disability Act (2006) was to enable the agencies to enact and enforce laws that protect and at the same time support the rights of people with disability. 
In Ghana, there are some teacher training institutions, particularly Post-secondary and teacher training colleges, University of Cape Coast, University of Ghana and the University of Education, Winneba, that train teachers to teach at the pre-tertiary educational level - thus, Preparatory, Kindergarten, Lower Primary, Upper Primary, Junior High and Senior High Schools. In Ghana, there are regulative and legislative frameworks that help enact laws aimed at protecting and sheltering SEND students (Tsikudo, 2019; Ankutse, 2019; Special Attention Project, 2011). It is, therefore, assumed that all those teachers who have gone through the curriculum of any of such teacher training institutions might have learnt and internalised the regulative and legislative frameworks for easy promulgation of laws or operating within the enacted laws in the schools in which they teach. More often than not the stake holders of education, students, parents, government, teachers and school administrators complain about biases against and alienation of students with SEND. These complaints are geared towards teachers, mostly, newly recruited teachers. However, these complaints are sometimes rumours without any empirical evidence.

Over the years, many researchers have shown interest in investigating into teachers' knowledge of students of SEND. Some of them looked at comparing the attitudes and self-efficacy of in-service educators when implementing methods that promote diversity and inclusion and its consequences for teacher education (Savolainen, Engelbrecht, Neil \& Olli-Pekka, 2012; Kurniawati, Minnaert, Mangunson \& Ahmed, 2012); assessing parents with SEN children's psychosocial and training needs (Okeke \& Mazibuko, 2014); examining attitudes of teachers and perceived knowledge of inclusive education (Mohamed, Ramlee, \& Jelas, 2006); evaluating the effective teaching practice for children with SEND (Buli-Holmberg \& Jeyaprathaban, 2016).

The literature is replete with the responsibilities and roles of the classroom teacher when it comes to dealing with SEND students (AASEP, 2006; Alkahtani, 2016; Okeke \& Mazibuko, 2014; UCLES, 2017). For instance, it is the duty of the classroom teacher to accommodate SEND students, assign special assignments with necessary modifications, focus on inclusiveness. The question worthy of answering is, "Why should there be complaints of biases against SEND students if such teachers have gone through the national professional curriculum and at the same time have read the literature which is replete with legislations?"

This study is to investigate into teachers' knowledge of SEND and their rights as enshrined in the regulations and legislations, and how such teachers are implementing such strategies in the classroom. This notion leads to the thesis that teachers' knowledge of SEND ultimately leads to effective classroom interaction and management as well as inclusivity. The study is guided by the following research questions: (1) What is the extent of teachers' knowledge of SEND in Ghana? (2) What is the level of teachers' knowledge of the concept of inclusivity in the classroom? (3) How conversant are teachers with the regulations and legislations that relate to SEND students? (4) What classroom management procedures do teachers adopt to help bring about inclusivity in the classroom? (5) What are the practical awareness strategies and management approaches that can help protect and promote the welfare of students with SEND?

\subsection{The Concept of Special Education and Disability}

The concept of SEND students has been looked at from different perspectives (Alkahtani, 2016, Benerjee, 2006; Kuyini et al., 2015; UCLES, 2017). For instance, Kuyini, et al. (2015) defines special education as an education aimed at strengthening the learning capability of children with SEND by providing their needs especially those who are not able to benefit easily from mainstream settings. There is a distinction between students in the mainstream and those in special institutions (Shaddock, Giorcelli \& Smith, 2007; Special Attention Project, 2011; Ankutse, 2019). Depending on the severity or otherwise of the SEN then the appropriate classification is made.

Sensory disabilities have been classified into intellectual disability, hearing impairment and visual impairment (Kuyini et al., 2015). Among the other forms of disabilities are Autism Spectrum Disorder (ASD), Social, Emotional and Behaviour Disorder; Learning Difficulties and Physical Disability (Alkahtani, 2016; UCLES, 2017).

Many theories have accounted for the learning difficulties. Among such theories are the Psychological model, the Behaviour model, the Cognitive model and the Cognitive Holistic model (Haug, 2010; Kuyini, et al. 2015). The Psychological model considers the neurons as the cause. Learning stems from the brain nerves so any problems related to the brain can bring about psycho-neurological learning disability (Kuyini, et al., 2015). The behaviour model believes that it is through well-structured and sequenced lesson that learning takes place and that there is nothing that cannot be learnt. On the side of the cognitive strategists, the blame should not be put at the door steps of the learner because the learner does not have any problem with learning but it is the teacher who is to blame. According to them, if the teacher is able to put learning into appropriate strategies then learning will take place. The cognitive holistic model also refers to a dysfunction in the central nervous system as the cause of learning impairment (Kuyini et al., 2015). According to them, people with learning disabilities are characterised by low 
intelligence, low and poor attention span, spelling, reading and understanding difficulties, poor handwriting and easily forgetting what is learnt (Haug, 2010; NCSE, 2013; Drabble, 2013; Shaddock, Giorcelli \& Smith, 2007).

\subsection{Special Educational Needs and Disability Education in Ghana}

Ghana operates within the context of global framework. The concept of SEND education did not originate in Ghana but as a necessity, Ghana needs to adopt and adjust global issues that may suit the needs of students. The suggested actions of UNESCO World Education Forum about the rights to educate every individual that was stated in the 1948 Universal Declaration of Human Rights had to be ratified by Ghana (Ankutse, 2019; Special Attention Project, 2011). These universal declarations are binding on nations and states to integrate them into their educational systems. UNESCO's (1994) Salamanca Statement and Framework for Action on SEN and the UN's Standard Rules and Equalisation of Opportunities for Persons with disabilities are both crucial and significant (Kuyini, et al., 2015) that they need to be integrated in educational systems throughout the world and Ghana is no exception. The provisions commit individual countries to provide an education free of individual differences (Drabble, 2013; Shaddock, Giorcelli \& Smith, 2007; NCSE, 2013).

Ghana's reaction to the universal declarations and countries' commitment was seen in the 2007 educational reforms which focused on Pre-schooling as an essential aspect of Ghana's education system and made basic or primary education eleven years (KG1-JHS3) (Ankutse, 2019; Oye-Lither, Stickney, \& Nathan, 2007). These provisional actions have already been catered for in the 1992 Constitution of the Republic of Ghana. It is stated that every child has the right to free compulsory universal basic education (FCUBE). Another important framework within which Ghana operates is the UN Convention on the Rights of the Child (UNCRC) and the Children's Act (560) of 1998 which serves as a major legislative tool in Ghana. The UNCRC also facilitates certain rights such as, basic needs, the right to life, freedom of speech, security, medical facilities, education and freedom of expression (Special Attention Project, 2011. The 1998 Children's Act (560) hinges on the UNCRC and it helps formulate laws on the rights of children to well being recognition and protection. This is the premise of the right of children to education and the beginning of inclusivity.

The concept of inclusivity was enshrined in 1994 UNESCO Salamanca Statement and Frame of Action on SEN (Ankutse, 2019; Oye-Lithur, Stickney, \& Nathan, 2007). In Ghana, the rights of persons with disabilities are enshrined in the 1992 Constitution of the Republic of Ghana (Acts 25, 26, 3738 and part of 39). One of the Articles, Article 37 (2), clearly spells out the appropriate provision crucial and appropriate for protecting and promoting basic human rights and freedoms. This Article states that the country will formulate laws to safeguard and promote all fundamental human rights and freedoms including those of the disabled, elderly, children and vulnerable groups during development processes. With regards to Article 38, it is the responsibility of the government to provide all school-aged children Free, Compulsory Universal Basic Education.

One of the major Acts in Ghana is the 2006 Persons with Disability Act (Act 715). In this Act, parents and carers or custodians of children with SEND are obligated to enrol them in school (Ankutse, 2019; Oye-Lithur, Stickney \& Nathan, 2007). The government is responsible to provide free education for those children with SEND. The Act did not end there but further obligates the government to set up special schools for those with SEND who are unable to attend mainstream schools. The government, through the Ministry of Education, is also obligated to provide the necessary facilities and equipment at least in each region so that SEN students can benefit from schools fully. The government is also obliged to provide training through the establishment of vocational, technical and professional teacher training institutions with special education curricula in at least each region for secondary school graduates who are unable to continue further formal schooling. It is also compulsory on the part of the schools never to discriminate against any individual with SEND by not refusing any child admission on the basis of disability (Ankutse, 2019; Oye- Lithur, Stickney \& Nathan, 2007).

\subsection{Characteristics and Responsibilities of Products of Teacher Training Institutions}

The curricula of the Teacher Training Institutions in Ghana are designed taking into consideration the concept of inclusiveness. In the implementation of policies and regulations that have been translated into the curriculum, there is shared responsibility among the stakeholders in education (Drabble, 2013; NCSE, 2013). The Ghana Education Service (GES) under the authority of the Ministry of Education (MoE) see to the effective implementation of the policies. The major role then lies with the heads, principals and school authorities (AASEP, 2006, Tsikudo, 2019). The school authorities play a very significant role in the implementation of policies of SEND. They, in collaboration with GES, have to see to it that policies on construction of buildings are implemented to the letter. Again, policies on inclusiveness are upheld and implemented. They see to the conducive learning environment for all. The most crucial role, however, lies with the classroom teacher (Special Attention Project, 2011). It is the classroom teacher who 
interacts with the SEND students. Such teachers, therefore, need to have some special characteristics (Ankutse, 2019). They need to be well versed in the policies concerning the SEND students. They need to have known every aspect of the curriculum that they have gone through before being appointed as teachers. Again, they need to be welcoming and their social relationship should be very strong and cordial (Schwab, Gebhardt, Krammer \& Gateiger-Klicpera, 2019). In addition, they need to be psychologically prudent to enable them to detect learners with peculiar difficulties. Those who are not aware of students with peculiar behaviours consider such students as rebellious or challenging students (Ankutse, 2019). They consider them as distractive and disrespectful. In short, they need to know their students very well to enable them to handle and interact with them.

\subsection{Classroom Management Approaches}

One of the major areas in which the role of the classroom teacher is seen glaring is his or her approaches to classroom management. In a classroom management scenario, the seating arrangement, instructional methods, lesson preparations and the activities are put into consideration (Drabble, 2013; Shaddock, Giorcelli \& Smith, 2007). The classroom teacher needs to identify those learners who need special care, for example, in terms of vision, and make sure they have the right place to sit. Such learners are usually placed in front to enable them to see very well. Again, if it is hearing impairment, the same seating arrangement could be made by letting them sit in front to enable them to hear well as the distance from where they sit to the teacher may be close.

The choice of instructional methods is one of the roles of the teacher in managing the classroom (European Commission, 2013). The teacher needs to use a variety of methods in order to meet individual learning needs. Some of the students may not be able to learn through the same method. Intended objectives set to achieve cannot be achieved through the use of the same method. Some learners also learn through the use of graphic organisers. The teacher, in the first place, needs to know his or her students well and on the basis of that he or she may choose the appropriate instructional methods in order to meet their peculiar needs (NCSE, 2013). The decision making on the choice of any method is at the lesson preparation level. In preparing the lesson, the capabilities and intelligent levels of the students come to mind (Buli-Holmberg, Jeyaprathaban \& Sujathamalini, 2016; Kuyini et al., 2015). It is on the basis of this that the teacher decides on the types of method to use. The lesson preparation also takes into consideration the resources available and how they are going to be used in the classroom. Again, it is at the lesson preparation level that the teacher presumes how the classroom is going to be managed in terms of groupings for discussion or otherwise. The activities are what the teacher guides the students to do in class and out of class. The activities need to be presumed during the lesson preparation and be actualised during delivery or presentation. The teacher needs to conceive in mind that all the activities should be learner centred because it is what the learner does that is what he or she learns but not what the teacher does. The activities must also be conceived in mind taking into consideration the capabilities and abilities of individuals in the classroom (Savolainen, Engelbrecht \& Olli-Pekka, 2012). In the classroom management approach, the key issues of seating arrangement, instructional methods, lesson preparation and implementation of presumed activities are very crucial. The teacher's role is very significant in such areas.

\section{Methods}

\subsection{Setting}

Ghana is divided into five zones namely the Northern, Volta, Ashanti-Brong Ahafo, Central and Eastern-Greater Accra zones. Each of the zones could be used for the study but the Eastern-Greater Accra, the southern zone, was selected for the study. The rationale for the selection of southern zone was that most teachers prefer teaching in the capital city, Accra, and it is usually rumoured that most of the best teachers are in Accra (Akyeampong, 2003). In this zone, monitoring and implementation of policies are very keen and specifically in Accra. Again, most schools in Accra are considered as the endowed institutions because of both material and human resources. The researchers wanted to conduct the study in this southern zone first and the findings will show whether a replication may be done in other zones of the country.

\subsection{Research Design}

The study used social constructivism as its paradigm so qualitative research was adopted. A descriptive case study of qualitative study was used because the study sought to explain some present circumstances (Yin, 2014). According to Yin, there is no formula for the use of case study but if the focus is on how and why some phenomena work then a case study can be used. This current study focuses on how teachers relate to students in terms of their knowledge in special educational needs and disability students (SEND). Again, the study sought to look at experiences in its 
real-life context (Robson, 2012). Finally, the study sought to provide a narrative account (Yin, 2014) and an in-depth investigation and rich description (Deakin \& Wakefield, 2013).

The population considered two issues: the selection of the schools and the teachers who could serve as respondents. This target population therefore gave every pre-tertiary institution in the Eastern-Greater Accra zone the opportunity to be part of the study. In this case, all the pre-tertiary schools in the zone - basic, junior high and senior high schools were targeted. Again, all the teachers in such schools were also targeted. Teachers were targeted because the focus of the study was to find out teachers' knowledge of SEND students.

The work needed an in depth study of knowledge of teachers' experience in terms of their knowledge of students with SEN. In this case, an information-oriented sampling frame was used with small samples of single cases (Flyvbjerg, 2004). The sampling frame was, therefore, related to the specific problem under study and this is framed in the following thesis that: "any recruited teacher who has gone through the curriculum of the professional training institutions in Ghana should have knowledge of SEND students in Ghana and be able to manage them effectively in a classroom situation."

A purposive sampling procedure was used in selecting key informants from the selected institutions. According to Maxwell (2006), a purposive sampling is a type of sampling in which specific people, event or setting are carefully chosen for valuable information concerning a phenomenon which can neither be obtained nor obtained from any other choice.

The sample size was chosen from the sample frame of the whole population. The selection was limited to only teachers because the purpose of the study was to find out teachers' knowledge of SEND during the period of their education and the translation of the theories into practical teaching and learning situations. In Ghana, teachers, irrespective of their specialisation, could be posted to teach at any level. It is today that directives are being made to conduct a survey of teachers who are teaching in schools that do not hold the requisite qualification (GES, 2019). In view of this, the sample size comprised those who have been duly posted to teach at the pre-tertiary level such as the Basic schools, Junior high schools and the senior high schools. In all, fourteen (14) teachers, eight (8) males and six (6) females, were selected for the study. In the selection of the sample size, the researchers selected only first degree holders, some of whom were diploma holders and others pursuing diploma programmes. The schools actually varied because the researchers wanted to have a wider survey of teachers. In view of this, two teachers were chosen from an individual school which means that not more than two teachers were chosen from the same school.

In the process of choosing the sample size, the researchers have to first of all confer with the headmaster academic of the school to find out any course that related to SEND students and consequently the teacher in charge of that course will automatically be selected. In view of this, a lot of schools were not qualified to be selected and even those teachers who assumed to have been teaching courses related to SEND students turned to be difficult to identify. The interviewers, however, had to settle on the headmaster's directives for the interview.

\subsection{Unit of Analysis}

The unit of analysis used was at the sentence level. The scope of the unit of analysis included the four sentence types - simple, compound, complex and compound-complex sentences. In an extended form, a phrase that was comprehensible enough in answering any of the questions during the interview was also included in the unit of analysis. It is also noteworthy that the unit of analysis was directly related to the research questions hence there were five cases that were considered and each case related to one of the five research questions.

\subsection{Data Collection Instruments}

Empirical data is usually required to help validate or otherwise a theory. In this study, one instrument of data collection, interview guide, was used to gather data from the informants. The interview guide, as an instrument, was used because it served as a dynamic guide for conversation (Marrie-Lou, Roos, Christiane \& Jorgen, 2011). Also, the researchers' interest was to find out the knowledge in SEND students (Paul, Kleinhammer-Tramill, \& Fowler, 2009), hence the need for dynamic conversations.

The interview guide was structured into five sections and this was being informed by the research questions posed earlier on. Each research question had a series of items that could be used to address the research question. The structure of the interview was therefore based on the type of research question. The analysis of the data was put into consideration in itemising the series of questions structured ahead of time to ask the respondents.

\subsection{Validity and Reliability of Instruments}

The concept of validity is more pronounced in quantitative research but in qualitative research concepts such as 
trustworthiness, credibility, transferability, conformability and dependability are used (Seidman, 2013). These concepts are used because of the behaviour of humanity. For instance, the probability of getting the same response from a participant when interviewed twice at different times is very less. The responses given at a given time may not be trusted at a different time when a different researcher interviews the respondent at different times and locations.

According to Seidman (2013), validity can be attained through the use of the three levels of the interview structure the focused life history, the details of experience and reflections on the meaning of the phenomenon. According to him, the three interview structure places participants' comments in context. The three separate interview structure calls for an account for idiosyncrasy which invariably checks for internal consistency. When a number of participants are interviewed, Seidman (2013) says, we can connect their experiences and check the comments of one participant against those of others hence, ascertaining validity and reliability. For example, if a participant's first interview reveals that during his or her first degree level he or she heard about SEND and even studies a course about SEND and in the second interview it is also revealed that such a candidate emphasises that he or she has never heard of SEND then we can connect the first interview with the second one and conclude that there is no validity because there is no consistency in his or her presentation.

\subsection{Data Collection Procedure}

The data was collected through an interview and it was collected personally by the researchers. The reason behind the choice was due to the ability to grant this study with detailed information about respondents' opinions, feelings and perception. An atmosphere of cordiality was created in order to avoid risks, deception, power relations and potential biases.

\subsection{Data Analysis}

Qualitative data analysis is established on quality as the name implies, and not on the numbers or quantities (Witte, Meyer \& Martell, 2001). The researchers got the data from the participants through tape-recording. Every word that was uttered from the participants was transcribed because paraphrasing what they said was considered as a substitute of the participants' consciousness with the researchers (Seidman, 2013). After the transcription, the large volume of information was reduced to the most significant information of interests. As the researchers identified the areas of interests and importance to the research question, they began with the analysis, interpretation and making meaning out of the transcribed information. The structured items within each research question were used to identify patterns, categories and themes. These patterns and themes were related to the research questions to help respond appropriately to them.

\subsection{Ethical Considerations and Informed Consent}

This research was carried out after receiving ethical approval from the University of East London. In doing so, the eight parts of an informed consent (Seidman, 2013) were followed. The purpose of interviewing the participants was explicitly outlined for the participants. This explicit purpose was followed by an outline of the potential risks of vulnerability or discomfort for the participants. The rights of the participants were also outlined and they helped in mitigating the risks of vulnerability and discomfort. Again, possible benefits of the study were given out to the participants. Furthermore, confidentiality of the participants' records was clearly stated.

The intention of and how the research findings should be disseminated were also outlined clearly. Access through gatekeepers was also considered. The teachers, principals and superintendents who serve as legitimate gatekeepers were appropriately contacted. They had the responsibility of operating the schools so they needed to be formally consulted

\section{Results}

\subsection{Responses to the Guided Questions}

In order to accurately answer the five guided questions, a series of items used in the structured interview were analysed. In view of this, each guided question with its related items is analysed.

Guided question (1): What is the extent of teachers' knowledge of SEND students in Ghana? In response to this question, items (a) to (g) on the interview structure were used. The researcher wanted to find out from item (a) whether the respondents have ever heard of the concept of SEND students in Ghana. All the fourteen (14) respondents answered positively that they had ever heard of SEND. The sources, item (b) of their information, however, varied. Out of the fourteen (14) respondents, only Interviewees eight (8) and thirteen (13) actually did a 
course in special educational needs:

I knew about them first because I did a course in special education. I went to the school of the Deaf in Mampong (Interviewee 8).

During my courses even right down to my diploma level or my education at the college level and I also did special education during my 1st degree and I am also doing inclusive education now (Interviewee 13).

The remaining twelve (12) respondents got to know about SEND either through their contact with one, colleagues, or read notices and through the media. For instance:

Interviewee 12: I heard it from the news, articles that I read for my personal consumption and when I was coming for interview for the masters program.

Interviewee 5: Walking on Legon campus, I sighted a sign board indicating the Office of students with special needs. That was my first point of knowledge of it.

Interviewee 10: We had a student with Down syndrome and he was a teacher's daughter and everyone had to play with her that was where I got to know it.

It can be deduced from the interview that all the respondents got to know about SEND but the majority (12) of them did not know it through their education at the training college or the university but through the general public. Only two got to know about it through formal educational programme. The respondents' knowledge in SEND is therefore very minimal.

Items (c) and (d) dealt with the respondents' qualifications and it was found that all the fourteen respondents have had their first degree certificates in recognised and accredited universities in Ghana. Items (e) and (f) were used to find out whether the concept of SEND was found in the curriculum of the schools the respondents attended and whether the respondents really did a course in SEND respectively. Interviewees one (1), two (2), eight (8) and thirteen (13) answered positively that the SEN as a course was found in their school curriculum and also they did a course in it. It was, however, realised that interviewee thirteen actually did a course in it and that course was found in the curriculum. This can be deduced from the following conversation:

Interviewer: In your first degree did you go through something related to this SEND issue? (2:11 - 2:13)

Interviewee 1: No, no.

Interviewer: But you did Psychology?

Interviewee 1: Oh yes, we did a topic in special needs. There was a topic we treated which covered people with disability and special needs.

Interviewer: So did you find the concept of SEND students in the curriculum during your first degree? (1:04 1:08).

Interviewee 2: Yes, the first degree

Interviewer: So, you did special education during your 1st degree?

Interviewee 13: Eh you know, it was part of the courses but not as a program.

Interviewer: Did you find the concept of SEND students in your school curriculum during the 1st degree?

Interviewee13: Yes.

Interviewer: Did you do a course in special educational needs and disability?

Interviewee 13: Yes.

The findings show that only a few actually did a course in special educational needs of students. This means that the majority of the teachers did not have the right educational training to enable them to handle the learners.

Item $(\mathrm{g})$ which sought to find out the overall impression of the respondents on their knowledge of SEND was used to conclude on guided question one.

Item (g) reads: What is your overall impression of your knowledge in special educational needs and disability students in Ghana?

All the fourteen informants expressed similar sentiments about their overall impression. While some were lamenting about their limited knowledge in SEND, others were suggesting ways and means of co-habiting with students with SEND.

For instance, Interviewee 3 responded: Emm, I think that many a time they are left out. Mainstreams do not consider 
special needs students even looking at how buildings are structured. Because you see, when I was at Legon, I never saw any lecture room purposely meant for SEND students. This lamentation is supplemented by Interviewee 8 who says: I think I need to learn more. I think it's quite low and my impression was that they should be made part of the mainstream. Sometimes they could be separated and other times they should be brought in.

The suggestion from Interviewee 13, reveals that such a respondent has an in depth knowledge in SEND. She looked at it from the point of view of policy to common sense and then to a piece of advice:

Oh, I think so far so good and I appreciate that policy guidance. I think our policies have enough laws to guide and protect SEND individuals. The layman will call it disability. In my school we are trying our best to follow the laws set by government to include such students; the only problem is that we don't have the resources to accommodate them. Inclusion is expensive. But I think as a society we need to embrace such people because it could be anyone in your family or even your child.

In all, the informants' knowledge in SEND seems to be limited to only a few and as teachers it is very important they are knowledgeable in SEND to enable them to handle students/pupils and be able to manage the classroom interactions. Many of the teachers have not been fully aware of the presence of some of these children even in the class they teach. The overall findings is in contrast to Ankutse's (2019) research findings that teachers need to have some special characteristics to enable them to handle or manage students with special educational needs.

Guided question (2): What is the level of teachers' knowledge of the concept of inclusivity in the classroom? In response to their awareness of the concept of inclusivity, all the fourteen (14) respondents were aware of it but the level of their awareness could not be well demonstrated. For example, when Interviewee 4 was asked how inclusivity is applied, this is what he said, "Em ... I have to identify them now that I have become aware and then know how to apply it." The implication of this response is that the respondent seems to be aware of it not long ago and he is now going to use his awareness to identify who they are before its application.

The response of Interviewee 4 is a direct opposite of Interviewees 12 and 13. In response to the question of how inclusivity in the classroom could be applied, Interviewee 12 said: "Children with low learning ability, struggle to stay focused and so on, we need to pay attention to them so we create task that suits their need with special guidance" (Interviewee 12).

This response is similar to the one given by Interviewee 13 because the underlying idea is to give support to those with challenges and to bring about equity. This is what Interviewee 13 said: Yes, inclusivity, you know everyone is unique and their traits and abilities, capacity, potential variations and each one needs to benefit from the class to the maximum with the maximum support from the teacher. It's good as teachers we monitor them with close observation and give them the maximum support (Interviewee 13).

In furtherance with the concept of inclusivity, the respondents were asked to declare their awareness of biases or exclusion in the classroom during teaching and learning situation. Eight (8) out of the fourteen (14) respondents responded in the negative way as they have not observed any biases or exclusion in the classroom. The remaining six (6), however, said they had observed and experienced some biases in the classroom teaching and learning situation. In order to get evidence of their observation, they were asked to give scenarios to support their claim. Interviewees 7 , 12 and 13 gave very pathetic scenarios:

Interviewee 7: Sometimes the one with dysgraphia, when I give an assignment he brings it for me to go through and guide him. I give him steps to follow and he shows it to me after each step before I mark. I give him more time as well. Sometimes he gets better grades or scores so the other pupils feel there is some bias.

Interviewee 12: Yes, sometimes, they feel you are paying too much attention to a particular child and they being children, they don't know that it is because of that disability that is why you are paying too much attention to them.

Interviewee 13: A student in my class with one eye damaged came crying to me one lunch time about his friends teasing him about his eye. This child was not born this way but was involved in an accident. I saw this as bullying. I called my class and had a lengthy talk with them and made them understand that in the first place bullying is not accepted in the school or in my class. And as a class we are a family and we respect people no matter their disability. My children understood this and apologised to the boy who calmed down after this. And I haven't had such complains ever since.

The responses from the respondents indicate that all of them were aware of the concept of inclusivity. However, their encounter with special needs students and the application of inclusivity in the classroom varied with few of them having in depth knowledge of scenarios of biases or exclusion. 
Guided question (3): How conversant are the teachers with the policies that relate to special educational needs and disability students? In response to this question, majority of the respondents (12) had knowledge of the policies but not all of them knew the documents in which such policies are embedded. For instance, five (5) out of the fourteen (14) respondents never had knowledge of the documents. Again, citing examples became very difficult for the respondents. Six (6) of them were able to cite examples of the policies. In terms of the sources of information of the policies, most of them declined to comment on that but two respondents said they got the information through the general public but not through schooling.

The effectiveness of the implementation of the policies became a major issue of discussion during the interview. Only Interviewee 8 said that the implementation of the policies was effective:

"I will say to a large extent. I think that for me personally now that I am doing a course in inclusive education, it makes me understand the students in my class who seemed to be stubborn. Now my attitude towards them will be different from previous approach. No specific law has been discussed at our school level: No strategies have been discussed at our school level to deal with children who display some of these challenges (Interviewee 8).

Interviewees 9,10,12 and 13, for instance, were of the view that the implementation of the policies has not been effective at all. This is what they had to say:

Interviewee 9: Hmmmm, to some extent, we don't have education on it. Most teachers or educators haven't been trained on it so some don't have the professional skills or technical know-how. It is difficult to treat these children if they are in your class.

Interviewee 10: I think they are just there for law purposes. I don't think they are effective.

Interviewee 12: It will have been effective but in the situation in which we find ourselves, a private school, some parents tell us that they don't want their children to mingle with those with disabilities so it makes it a bit difficult. Sometimes some parents even withdraw their so called normal children from the school due to those with physical challenges. So, you are also careful with the kind of disability you admit. For hearing impairment, that one is manageable because it is not very obvious. Those with dysgraphia too you can admit them; Autistic, Down syndrome ones you are careful when you admit them into your school. So, it is not so effective.

In view of the ineffectiveness of the implementation of the policies, many of the respondents suggested that there should be strict implementation of the policies. Most of them were against a review of the policies because the policies were clearly stated in the documents but it was the implementation that needed enforcement. Interviewee 5, for instance, insisted on education: Emm ... well, before I talk about review I think there is need for more education for institutions to include in their infrastructural facilities that help them to have access to teaching and learning.

Even though the respondents claimed to have knowledge in the policies, they seemed not to have gone through any specific training, for example, through education in order to be well versed in them. Again, the respondents seemed to have knowledge in the policies through the general public more than through the educational system. Some of the respondents were pursuing their Masters Degree programmes and they claimed to have heard of the policies through such new programmes.

Guided question (4): What classroom management procedures do teachers adopt to help bring about inclusivity in the classroom? With regard to seating arrangement, almost all the respondents claimed that a mixture of boys and girls is the normal seating arrangement without any consideration of who the learners are. Only one respondent claimed that those with impairment would be asked to sit in front in order to see clearly on the board. One underlining reason for mixing the learners in their seating arrangement is that those identified learners with challenges attend mainstream schools where there is no pronounced discrimination.

The respondents suggested many strategies to adopt in order to create awareness both in the class and outside the class in order to bring about inclusivity in the classroom. While some of the respondents suggested advertising in the media (Interviewee 3), talking about it in class (Interviewee 4), showing films on disability and to learn a lesson from it (Interviewee 5), giving helping hand and helping them to board vehicles (Interviewee 6), explaining to other teachers who are not aware of inclusivity (Interviewee 7), educating the masses using both formal and informal approaches (Interviewees $8 \& 11$ ), et cetera, others suggested inculcating the idea of inclusivity into stories for children, especially at the lower level (Interviewee 10) and embracing them as a social responsibility (Interviewee 11).

Some of the management strategies both in and outside of the classroom were really appealing. Interviewees $2,6,8$, 12 and 13 made the following management strategies: 
Interviewee 2: I will talk to them that we are all human beings; eh we are the same, and that we should keep each other because we are all capable in one way or the other; we have to encourage one or another to live together.

Interviewee 6: Emm ... if I identify one in class, first of all you have to make it known to the students by explaining that it's no fault of hers or his. As human beings we're brothers and sisters so we should learn to support each other. And also, as a teacher I will find means and ways of teaching so that such a student is not left out.

Interviewee 8: I think for me I have even started with the teachers in my school. The last time I visited the school I spoke to my boss about that particular child in my class who had the dysgraphia problem; he forgets everything. I spoke to her that he had some specific disability but then in Ghana some parents don't want to tag their children with specific disabilities so we discussed how to adopt some strategies at the school level to deal with it; now then that we can attribute the behaviour to disability it makes us understand him better so we can think of a better way of helping him do better. So, I think in my school during staff meetings we may discuss some of these issues and I will also discuss with other teachers too.

Interviewee 12: If you come into contact with them may be at church, in social gathering, you can educate them; educate parents so that they can educate their children.

Interviewee 13: One of the ways is when we have the opportunity of meeting with parents thus PTA meetings sometimes these issues come on board and we deliberate on them to send some signal to them. Sometimes within the community the people can tease others that they are dumb, deaf and even demonstrate it to their face so they need to be educated that no one is happy to be a disabled person so don't tease those who are already in that category. If we do that we are treating them unfairly.

In analysing the responses of the informants, it could be deduced that if the teachers themselves become aware of the challenges of SEND, they are the right people to educate the masses on how to manage them both inside and outside the classroom. It is only when one is well versed in a concept that the one stands a better chance in educating others about the same concept.

Guided question (5): What are the practical awareness strategies and management approaches that can help protect and promote the welfare of SEND? There are many ways, according to the respondents, of protecting and promoting the welfare of learners with special needs and those with disability. One of the means is to bring them closer to ourselves and to create avenues for them to be catered for (Interviewee 3). Another way of protecting and promoting their welfare is to set up an office for them and give them special attention (Interviewee 5). Again, we can protect and promote their welfare by providing them relevant resources and making sure of effective implementation of policies regarding SEND students (Interviewees 8 \& 12).

One of the important means of protecting and promoting the welfare of SEND students is to create confidence in themselves. This is craftily presented by Interviewee 13: Well, for me on my side what could be done or I can do is to enhance on their confident level for them to come to accept themselves as what they are now and also to understand that that is not the end. They can do well if they tap into other strengths they can exploit. For example, if you are blind it doesn't mean you are dumb; it doesn't mean your brain is not working.

\section{Discussion}

In the discussion of guided question one, it was realised that the respondents' knowledge in SEND was very minimal. Buli-Holmberg \& Jeyaprathaban (2016) found in their study that minimal knowledge in SEND may lead to neglect of learners with special needs According to them, it is only through one to one relation that learners with special needs get support but in general, those with SEN who need support do not get it.

The findings further revealed that majority of the teachers did not have the right educational training to enable them to handle the learners as most of them did not do a course in SEND. The outcome of this study contradicts that of Schwab, Gebhardt, Krammer and Gateiger-Klicpera's (2019) findings that teachers need to be well versed in the curriculum to enable them to relate socially with the learners. According to them it is only when teachers are well versed in the curriculum that they may be welcoming and their social relationship with students with special needs will be strong and cordial.

With regard to inclusivity, only few of them had an in-depth knowledge of it and its application in terms of one to one interaction. Buli-Holmberg and Jeyaprathaban (2016) found that when there is one to one relationship between teacher and learner then the learner gets the needed support. Again, according to the findings, even a small group class of SEND brings about positive support for students with special educational needs. 
Another area of concern was the educational policies regarding students with special needs. The study revealed that the respondents were not well versed in the policies guiding students with special needs as such students were being considered as stubborn or rebelious. Ankutse (2019) and Schwab, Gebhardt, Krammer and Gateiger-Klicpera (2019) found in their research that it is only when teachers are well versed in the policies that they will be able to implement them. Again, they found that teachers who are not well versed in the policies and are not aware of students with peculiar behaviours consider such students as rebellious or challenging. Thus, teachers need to be psychologically prudent to enable them to detect learners with peculiar difficulties (Ankutse, 2019).

The respondents admitted the importance of bringing about inclusivity in the classroom in the management of the class. This builds on research findings in the literature (Drabble, 2013; Buli-Holmberg, Jeyaprathaban \& Sujathamalini, 2016; European Commission, 2013; NCSE, 2013). According to literature and research findings, classroom management includes seating arrangement, instructional methods, lesson preparation and delivery (Drabble, 2013). It is through the choice of a variety of instructional methods that the learner with special needs is catered for in the classroom management procedures (European Commission, 2013; NCSE, 2013). Again, the importance of teacher's lesson preparation lies in the determination of the capabilities of the learners (Kuyini et al., 2015; Savolainan, Engelbrecht \& Olli-Pekka, 2012).

\section{Conclusion}

The rationale for the study was to determine the level of teachers' knowledge of SEND students in classes that they teach, determine their knowledge of the concept of inclusivity in the classroom, explore their awareness and understanding of regulative and legislative frameworks that relate to SEND students, examine classroom management procedures that teachers adopt in managing SEND students and to finally explore possible awareness strategies and management approaches. Through qualitative paradigm and a descriptive approach, data were gathered from respondents, transcribed and thematically analysed.

The study showed that teachers' knowledge of SEND students was very superficial. Again, it was found that their knowledge of the concept of inclusivity was known through the general public with the exception of very few of them who got to know it through formal education. Due to the limited knowledge in inclusivity, its application in the classroom was very low. In addition, teachers' knowledge in the policies enshrined in the constitution of Ghana and in the various Acts was very minimal. Furthermore, classroom management procedures that teachers used were mostly appropriate though many other management strategies suggested by the literature were not applied. The awareness and creation of the strategies for protecting and promoting the welfare of students with SEND were very encouraging.

The findings of the study have mixed reactions. While some of the findings built upon the existing literature, some of them raise further questions about the academic and professional qualification of the respondents. Again, while some of the findings support the existing research findings, others contradict research in the field.

\subsection{Recommendations}

On the basis of the findings, it is recommended that teachers need to be examined appropriately and certified before allowing them to teach in schools. This suggestion welcomes the Ministry of Education's effort to make it a policy for all teachers to write Licensure Examination for teacher certification before they may be allowed to teach. Those teachers who are already on the field teaching should be updated with the current trend of educational issues including inclusivity, equity and gender sensitivity. This can be done through Continuous Professional Development (CPD) programmes, in-service training and through workshops.

\section{References}

AASEP (2006). Staff development in special education: Roles and responsibilities of the special education teacher. Pierangelo/Josey Bass Publishers.

Akyeampong, K. (2003). Teacher Training in Ghana-Does it count? (Muster Country Report One). Sussex, UK: DFID.

Alkahtani, M. A. (2016). Review of the literature of children with special educational needs. Journal of Education and Practice, 7(35), 70-83.

Ankutse, N. (2019). Overview of policy and legislative framework on inclusive and special education in Ghana. Compilation of special needs, policies and legislative framework. Accra, Ghana. 
Banerjee, B. (ed.) (2006). (NCERT) (2006). Education of children with special needs. National Council of Educational Research and Training.

Buli-Holmberg, J., \& Jeyaprathaban, S. (2016). Effective Practice in Inclusive and Special Needs Education. International Journal of Special Education, 31(1), 119-134.

Cohen, L., Manion, L., \& Morrison, K. (2007). Research methods in education (6th ed.). New York: Routledge Constitution of the Republic of Ghana (1992). Republic of Ghana. https://doi.org/10.4324/9780203029053

Deakin, H., \& Wakefield, K. (2013). Skype interviewing: Reflections of two PhD researchers. Qualitative Research, 14(5), 603-616. https://doi.org/10.1177/1468794113488126

Department for Education and Department of Health (2015). Special educational needs and disability code of practice: 0 to 25 years.

DfES (2016). World class education and care. London: TW9 4DU. Retrieved from https://gov.uk/government/uploads/system/uploads/attachment_data/file/398815

Drabble, S. (2013). Support for children with special educational needs (SEN). RAND: European Union.

Edyburn, D. L. (2001). Models, theories and frameworks: Contributions to understanding special education technology. Retrieved from https://www.freewebs.com/sallydoxie/SETmodels

European Commission (2013). Support for children with special educational needs. Employment, social Affairs and Inclusion - RAND Europe.

Flyvbjerg, B. (2004). Five misunderstandings about case study research. In C. Seale, G. Gobo, J. F. Gubrium \& D. Silverman (Eds.), Qualitative Research Practice (pp. 420-434). London and Thousand Oaks, CA: Sage. Retrieved from https://doi.org/10.4135/9781848608191.d33

Ghana Education Service (GES) (2019). Withdrawal of distance and sandwich trained teachers in senior high schools. Accra.

Haug, P. (2010). Approaches to empirical research on inclusive education. Scandinavian Journal of Disability Research, 12(3), 199-209. https://doi.org/10.1080/15017410903385052

Kachembele, M. (2018). Various models use in the provision of special educational needs and their strength and weakness. Retrieved from https://unza-zm.academia.edu/mwenyakachembele

Kurniawati, F., Minnaert, A., Mangunson, F., \& Ahmed, W. (2012). Empirical study on primary school teachers' attitudes towards inclusive education in Jakarta, Indonesia. Social and Behavioral Sciences, 69, 1430-1436. https://doi.org/10.1016/j.sbspro.2012.12.082

Kuyini, et al. (2015). Disability rights awareness and inclusive education: Building capacity of parents and teaches. UN, UN Voluntary Fund on Disability.

Marie-Lou, H. C., Roos, W., Christiane, T., \& Jorgen, C. (2011). Instruments and guidelines for qualitative fieldwork. EUMAGINE Project Paper 6B.

Maxwell, J. A. (2006). Literature reviews of, and for, educational research: A response to Boote and Beile. Educational Researcher, 35(9), 28-31. https://doi.org/10.3102/0013189X035009028

McMillan, J. H. (1996). Educational research: Fundamentals for the consumer (2nd ed.). New York: HarperCollins Publications Incs.

Mohamed, M. B., Ramlee, M. A., \& Jelas, M. Z. (2006). An empirical study on teachers' perceptions towards inclusive education in Malaysia. International Journal of Special Education, 21(3), 36-44.

NCSE (2013). Supporting students with special educational needs in schools. National Council for Special Education.

Okeke, C., \& Mazibuko, G. F. (2014). The experiences of parents of school children with special education needs: An empirical study. Mediterranean Journal of Social Sciences, 5(15), 227-240. https://doi.org/10.5901/mjss.2014.v5n15p227

Oye-Lithur, N., Stickney, S., \& Nathan, S. (2007). The simplified version of disability rights in Ghana. Accra: Commonwealth Human Rights Initiative.

Paul, J., Kleinhamner-Tramill, J., \& Fowler, K. (2009). Qualitative research methods in special education. Colorado: Love Publishing Company. 
Persons with Disability Act (2006). Persons with disability Act. Accra, Ghana.

Reimer. B. (1980). Building an aesthetic education curriculum: A model and its application. The High School Journal, 64(2), 36-49.

Robson, C. (2011). Real world research: A resource for social-scientists and practitioner-researchers (3rd ed.). Oxford: Blackwell Publishing.

Rousan, F. (1998). Issues and problems in special education. Amman: Dar-Fikr for printing.

Savolainen, H., Engelbrecht, P., Nel, M., \& Olli-Pekka, M. (2012). Understanding teachers'attitudes and self-efficacy in inclusive education: implications for pre-service and in-service teacher education. European Journal of Special Needs Education, 27(1), 51-68. https://doi.org/10.1080/08856257.2011.613603

Seidman, I. (2013). Interviewing as qualitative research: A guide for researchers in education and the social sciences (4th ed.). New York: Teachers College Press.

Schwab, S., Gebhardt, M., Krammer, M., \& Gasteiger-Klicpera, B. (2019). Linking self-rated social inclusion to social behaviour. An empirical study of students with and without special education needs in secondary schools. Retrieved from https://www.researchgate.net/publication/264238043

Shaddock, A., Giorcelli, L., \& Smith, S. (2007). Students with disabilities in main stream classrooms: A resource for teachers. Commonwealth of Australia.

Special Attention Project (2011). Children with learning difficulties in public basic schools in Ghana: A study involving local stakeholders in Greater Accra. Retrieved from www.sapghana.com

Tsikudo, M. (2019). Roles and responsibilities of stakeholders in inclusive education. Presentation on a day Workshop on Inclusive Education for Circuit Supervisors, some Selected Heads and Some Senior Staff from Municipal Education Office, Ho Municipal Education Directorate, Ghana.

Turnbull, H. R., \& Stowe, M. J. (2001). Five models for thinking about disability: Implications for policy responses. Journal of Disability Policy Studies, 12(3), 198-205.

UCLES (2017). Special educational needs. Cambridge: Cambridge Assessment International Education.

UNESCO (1994). The Salamanca Statement and Framework for Action on Special Needs Education. Paris UNESCO.

Witte, K., Meyer, G., \& Martell, D. (2001). Effective health risk messages: A step-by-step guide. SAGE Publications, Inc. http://dx.doi.org/10.4135/9781452233239

Yin, R. K. (2014). Case study research design and methods (5th ed.) Thousand Oaks, CA: Sage.

\section{Copyrights}

Copyright for this article is retained by the author(s), with first publication rights granted to the journal.

This is an open-access article distributed under the terms and conditions of the Creative Commons Attribution license (http://creativecommons.org/licenses/by/4.0/). 